\title{
Bond Strength of Super-CFRP Rod in Concrete
}

\author{
Sung-Tag Seo ${ }^{1)}$
}

(Received December 10, 2004, and accepted May 26, 2006)

\begin{abstract}
Elastic modulus, tensile and bond capacities are important factors for developing an effective reinforcing action of a flexural member as a reinforcing material for concrete structures. Reinforcement must have enough bond capacity to prevent the relative slip between concrete and reinforcement. This paper presents an experimental study to clarify the bond capacity of prestressed carbon fiber reinforced polymer(CFRP) rod manufactured by an automatic assembly robot. The bond characteristics of CFRP rods with different pitch of helical wrapping were analyzed experimentally. As the result, all types of CFRP rods show a high initial stiffness and good ductility. The mechanical properties of helical wrapping of the CFRP rods have an important effect on the bond of these rods to concrete after the bond stress reached the yield point. The stress-slip relationship analyzed from the pull-out test of embedded cables within concrete was linear up to maximum bond capacity. The deformation within the range of maximum force seems very low and was reached after approximately $1 \mathrm{~mm}$. The average bond capacity of CF20, CF30 and CF40 was about 12.06 $\mathrm{MPa}, 12.68 \mathrm{MPa}$ and $12.30 \mathrm{MPa}$, respectively. It was found that helical wrapping was sufficient to yield bond strengths comparable to that of steel bars.
\end{abstract}

Keywords: bond stress, pullout test, carbon fiber reinforced polymer, anchorage, adhesion.

\section{Introduction}

Reinforced concrete structures have been playing a key role in buildings and infrastructures since it was first applied to the bridge construction in the early of 19 th century. In modern time when structures are built densely in larger number, it is difficult to expect good-quality reinforced concrete structures because the use of sea sand is inevitable and skilled workers have been decreasing. Furthermore, the environmental issues like proper disposal and the recycling of wastes has increased. Especially, there has been increasing interests in the conservation of energy, saving of resources, and environmental preservation in the construction industry.

Carbon Fiber Reinforced Polymer (CFRP) material has been used in automobile, electronics and aerospace engineering. But, its application in such fields as the construction industries and automobile industry has been limited. Because the cost of first-generation CFRP is very high, its initial construction cost is $2-3$ times the cost of existing reinforced concrete system. Furthermore, bending moment and twist stiffness are weak compared with the steel. In order to solve these problems, a new system of constructing CFRP was developed at Kyushu University. The CFRP are constructed using an automatic assembly robot. This is called UCAS (Unidirectional Carbon Assembly System).

In general, reinforcement must be bonded well to the concrete matrix if the reinforced concrete is to perform well. Although the

1) KCI member, Dept. of Civil Engineering, Kyungil University, Gueongsan 712-701, Korea. Email: seosuntae@yumail.ac.kr Copyright (C) 2006, Korea Concrete Institute. All rights reserved, including the making of copies without the written permission from the copyright proprietors. bonding properties required for the reinforcement usually depend on the proportions or type of the structural members, there are cases in which higher bonding properties of the CFRP reinforcement are required, because the CFRP reinforcement possess very high strength. Comparing the bond behavior of fiber reinforced polymer(FRP) to that of steel reinforcing bars, it has been noted that some properties of FRP reinforcing bars can be remarkably different from those of deformed steel reinforcing bars. The lower lateral stiffness can influence splitting failure in bending conditions, and lower shear strength and stiffiness of ribs can influence the mechanical interlocking and the failure mechanisms in both splitting and pullout failure.

The mechanics of stress transfer by the bond between FRP rods and concrete have been investigated by many researchers, with respect to several types of bars characterized by various surface configurations, by different quality and quantity of fibers, and by the use of different resins as binders. From the experimental results, it is possible to observe that the bond of FRP reinforcement to concrete is controlled by several factors such as the following; chemical bond, friction due to surface roughness of FRP rods, mechanical interlock of the FRP rods against the concrete, hydrostatic pressure against the FRP rods due to the shrinkage of hardened concrete, and swelling of FRP rods due to the temperature change and moisture absorption. During initial pullout, the chemical bond (adhesion) is the main resisting mechanism. Afterwards, it is replaced by friction and/or mechanical interlock. Since the chemical bond between concrete and FRP is extremely low in general, friction and mechanical interlock become the primary means of stress transfer.

Chajes et al. studied the bond and force transfer mechanism in 
composite material plates bonded to concrete. ${ }^{1}$ Tests were performed using a single-lap shear test specimen and a constant bond length to evaluate the effect of surface preparation, type of adhesive, and concrete strength on average bond strength. Additional tests were performed to study the force transfer from the composite material plates to the concrete. In all bond tests, the composite plate was loaded under tensile force, resulting in the load increasing monotonically to failure.

Smooth FRP rods, manufactured through pultrusion, suffer from weak adhesion to the surrounding concrete, and additional means to improve the bond are needed. ${ }^{2}$ Several methods were developed in order to improve the bond capacity, mainly by application of deformations on the surface using different techniques. Benmokrane et al. found that application of deformation by double wrapping of helical wrapping around the rod significantly improved the bond. ${ }^{3}$ Other means such as machined rods, embedding sand particles on the surface, and roughening by sand blasting were discussed by Cosenza et al. ${ }^{4}$

Given the high social and financial costs associated with the repair of existing corrosion-damaged reinforced concrete infrastructure, and with the increasing attention being paid to energy conservation and environmental preservation in the construction industry, a number of manufacturers have started developing nonferrous reinforcement as alternatives to the conventional steel in traditional structure. ${ }^{5}$ Currently, many man-made fibers are used with the most common being glass, carbon, and aramid. These materials are characterized by very high levels of stress, well in excess of that of reinforcing steel. ${ }^{6}$ Still, although these advanced materials have served as a solution to the corrosion problem in steel reinforcement, their production cost is relatively expensive.

A material worth taking a look at is the Carbon Fiber Reinforced Polymer (CFRP), which has been used in automobile, electronics and aerospace engineering. ${ }^{7}$ Its application in the field of construction engineering has been rather limited compared to that of steel and concrete because currently available CFRP materials are expensive, with an initial structural construction cost that is about twice that of the conventional reinforced concrete system. Furthermore, CFRP has inferior mechanical properties compared to steel. ${ }^{8}$

In order to overcome these disadvantages, a new system to produce pre-stressed CFRP Rods was developed in this research, by using an automatic assembly robot (named UCAS System) at Kyushu University.

The aim of the experimental research is to quantify the bonding properties of pre-stressed carbon fiber reinforced polymer (CFRP) rod with concrete by conducting a set of experiments. The set of experiments would involve pullout tests using vertical bond specimens. The pullout test was aimed to investigate the bond capacity of CFRP.

A method for increasing the mechanical bonding of the CFRP, which is manufactured by assembling robot in Kyushu University, was studied. The new generation of CFRP bars had similar diameter of about $6.9 \mathrm{~mm}$. A steel bar of $6 \mathrm{~mm}$ diameter was used for the comparison of results. In this paper, the experiment investigates the bonding behavior of CFRP embedded within concrete.

\section{Manufacturing process of super-CFRP rods}

In this study, carbon fibers manufactured by Toray Co. Ltd. as shown in Fig. 1 were used. Mechanical properties of carbon fiber are listed in Table 1. The part nomenclature of these carbon fibers is T700S-12K. The carbon fibers used in this study consists of 12000 parallel filaments in one strand. The diameter of the filaments is $0.7 \mu \mathrm{m}$. The section area of strand is $0.46 \mathrm{~mm}^{2}$. The tensile strength, Young's modulus and weight density of carbon fiber strand used in this study are $4800 \mathrm{MPa}, 230 \mathrm{GPa}$ and $1.82 \mathrm{~g} / \mathrm{cm}^{3}$, respectively.

A carbon fiber strand is not suitable for construction engineering application without being impregnated into a resin matrix, to be shaped into the form of a rod or cable. The decrease in the tensile strength of conventional CFRP rods can be attributed to the concentration of the stress in certain fibers and to the uneven distribution of applied stress arising from improper manufacture.

In the conventional CFRP manufacturing process, the FRP rods are produced by pultrusion. The fibers are bundled together and drawn through a resin mix then pulled through a shaping die. As the rod emerges from the shaping die, it passes through a curing chamber where the resin is allowed to harden.

In using the UCAS method, the rod was manufactured carefully under constant tensile forces $1080 \mathrm{MPa}$ using an assembly robot. The rod was manufactured by first turning the longitudinal resinCF strands between two anchors under constant tensile forces, and then by wrapping the rod with a CF strand with resin. Due to the constant tensile forces, the stress concentration in the fibers could be avoided and a uniform transfer of force into the fibers could be achieved. Besides the increase in the resin strength due to the confinement effect of the wrapped carbon fiber strands, it was possible to reduce the pore in the rod.

An experimental evaluation of mechanical properties was carried out by performing tensile tests, which were conducted using a universal testing machine. To avoid gripping problems due to the low transverse strength of the reinforcing bars, a gripping system based on embedding both ends of the CFRP reinforcing bar into a metal tube was adopted, and the bond between the reinforcing bar and the steel tube was assured by an injection of expansive cement mortar.

The tests confirmed its linear elastic behavior up to failure. It

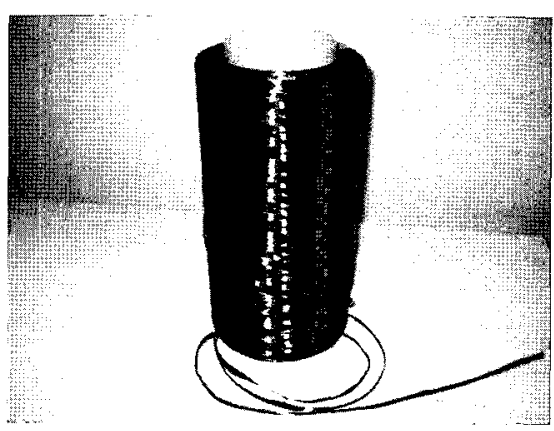

Fig. 1 Parallel carbon fiber.

Table 1 Mechanical properties of carbon fiber and resin.

\begin{tabular}{l|c|c|c|c|c|c}
\hline \multirow{2}{*}{$\begin{array}{c}\text { Material } \\
\text { name }\end{array}$} & \multicolumn{2}{|c|}{ Strength(MPa) } & Young's modulus & $\begin{array}{c}\text { Density } \\
(\mathrm{GPa})\end{array}$ & $\begin{array}{c}\text { Area } \\
\left(\mathrm{g} / \mathrm{cm}^{3}\right)\end{array}$ \\
\cline { 2 - 7 }$\left(\mathrm{mm}^{2}\right)$ \\
\hline \hline $\begin{array}{l}\text { Carbon } \\
\text { fiber } 12 \mathrm{~K} \\
\text { strands }\end{array}$ & 4,800 & - & - & 230 & 1.82 & 0.46 \\
\hline Resin & 29.4 & 68.6 & 9.8 & - & - & - \\
\hline
\end{tabular}


Table 2 Properties of super cfrp rod and steel bar.

\begin{tabular}{c|c|c|c|c|c}
\hline Type & Nominal diameter $(\mathrm{mm})$ & Cross sectional area $\left(\mathrm{mm}^{2}\right)$ & Tensile strength $(\mathrm{MPa})$ & Modulus of elastic $(\mathrm{GPa})$ & Ultimate strain $(\mu)$ \\
\hline \hline Super CFRP rod & 6.9 & 37.8 & 2,020 & 120 & 15,500 \\
\hline Steel bar D6 & 6.4 & 31.7 & 368 & 200 & \\
\hline
\end{tabular}

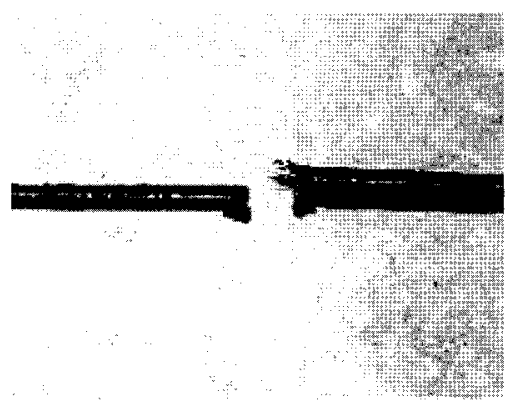

Fig. 2 Tensile failure of CFRP rebars.

was not possible to expect where the carbon fiber in rods would be broken in place. When the rod reached its maximum capacity, a big high-pitched sound was heard and the rod was broken simultaneously in several places. The failure mode of CFRP rods occurred near the center and anchoring parts, respectively, as shown in Fig. 2. But the ultimate stress was almost the same in all cases.

The experimental average values of the elastic modulus and the tensile strength are summarized in Table 2 for Super CFRP rod. The cross sectional areas of Super CFRP rod and steel bar are $37.8 \mathrm{~mm}^{2}$ and $31.7 \mathrm{~mm}^{2}$, respectively. This CFRP rod has tensile strength of 2,020 MPa with Young's modulus of $120 \mathrm{GPa}$.

\section{Experimental program}

\subsection{Specimen}

Straight CFRP rods will be used both for smooth rods and for rods obtained by an external surface process that does not provide ribs or indentations (i.e., for grain-covered and sandblasted rebars). The available tests have widely shown that two components of bond (adhesion and friction ) appear for the case of straight rebars. Therefore, there is no significant contribution of mechanical interlocking.

In order to improve bond behavior between concrete and CFRP rebars, three types of CFRP rods assembled by robot were tested and compared with ordinary deformed steel bars (Table 3 ). All the rods had a helical fiber wrapped around the surface to enhance the bond to the concrete as shown Fig. 3. The pitch of helical wrapping was assumed to be a parameter of $20 \mathrm{~mm}, 30 \mathrm{~mm}$ and $40 \mathrm{~mm}$.

\subsubsection{Concrete}

The proportion of the concrete used in this experiment is shown in Table 4. Ordinary concrete was prepared in the following composition $\left(\mathrm{kg} / \mathrm{m}^{3}\right)$; coarse aggregate, $1,079 \mathrm{~kg}$; sand, $660 \mathrm{~kg}$; ordinary Portland cement, $419 \mathrm{~kg}$; and water, $176 \mathrm{~kg}$. The average compressive strength was $28.3 \mathrm{MPa}$ after curing for 14 days.

\subsubsection{Specimens' description}

Specimens were prepared from a $1 \mathrm{~m}$ long rod embedded in a concrete block having dimensions of $100 \times 100 \times 100 \mathrm{~mm}$, as shown in Figs. 4 and 5. ${ }^{9}$ Bond breakers with a length of $50 \mathrm{~mm}$ were used at both ends of the concrete block to minimize the stress concentration near the concrete surface.

The anchorage systems used in this study is shown in Fig. 6. The anchorage sleeves were a cylindrical steel tube with a $20 \mathrm{~mm}$ of inner diameter and a $34 \mathrm{~mm}$ of outer diameter. The modulus of elasticity and poisson's rate of sleeve were $195 \mathrm{GPa}$ and 0.3 , respectively. A sleeve anchor system with expandable mortar was used for the specimen. The cement grouts had a water-cement

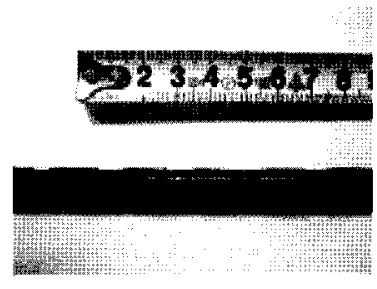

(a) CF20

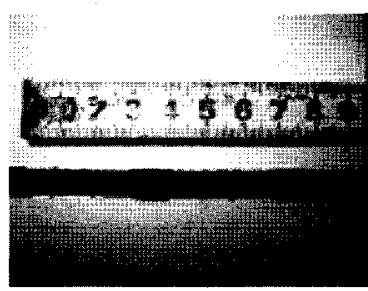

(c) CF40

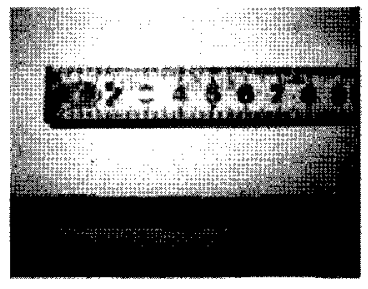

(b) $\mathrm{CF} 30$

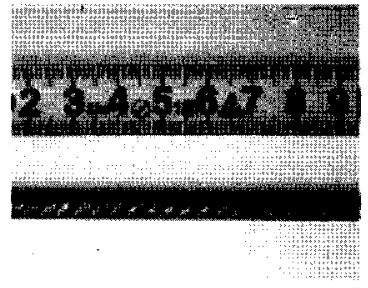

(d) SB

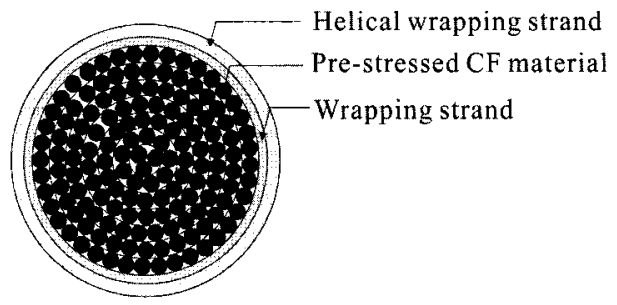

(e) Section of rod

Fig. 3 Images of tested rods.

Table 3 List of specimens.

\begin{tabular}{c|c|c|c|c|c}
\hline Types & Material & Number of turning & Diameter $(\mathrm{mm})$ & Pitch of helical wrapping (mm) & Embedded length (mm). \\
\hline \hline CF10 & Carbon fiber & 20 & 6.6 & 10 & 50 \\
\hline CF20 & Carbon fiber & 20 & 6.6 & 20 & 50 \\
\hline CF30 & Carbon fiber & 20 & 6.6 & 30 & 50 \\
\hline CF40 & Carbon fiber & 20 & 6.6 & 40 & 50 \\
\hline SB & Steel & D6 & 6.6 & & 50 \\
\hline
\end{tabular}


Table 4 Properties of concrete(average).

\begin{tabular}{c|c|c|c|c|c|c|}
\hline Temperature of concrete $\left({ }^{\circ} \mathrm{C}\right)$ & Slump & Air content $(\%)$ & Compressive strength(MPa) & Tensile strength (MPa) & Modulus of elastic (GPa) & Poisson's ratio \\
\hline \hline 12 & 16.7 & 4.7 & 28.3 & 2.17 & 22.9 & 0.2 \\
\hline
\end{tabular}

ratio of 0.28 . The compressive strength was $73 \mathrm{MPa}$ after curing 7 days at $20^{\circ} \mathrm{C}$.

\subsection{Loading program}

The specimens were demolded at 3 days after casting and tested after they were cured for 14 days. Strain gauges were attached to all of vertical side of concrete cubes to measure the strain on the concrete. The loading system of this experiment is presented in Fig. 7. As shown in Fig. 7, the specimen is placed on the load cell with center hole so that the CFRP can be connected to anchor through the hole of the load cell. Generally, devices that used in this experiment consist of two fixed and moveable parts. The specimen is placed on the fixed part while the CFRP rod is anchored on the moveable part. When the moveable part move down, the CFRP rod that are embedded vertically within concrete cubes will pull out. To measure the slip at the free end of CFRP rod, deformeter is set up on the free end of CFRP. And then, to measure how far the moveable part move down, two deformeters are set up at the top of the part as shown in Fig. 7. Also, there are another deformeters set up to measure whether the fixed bar move or not. All of the measured data are recorded by the data logger. In testing, data is recorded for each and every applied load of about $98 \mathrm{~N}$ until peak load is reached. After that, the recording data is controlled by slip that occurs until the specimens lose its bonding capacity.

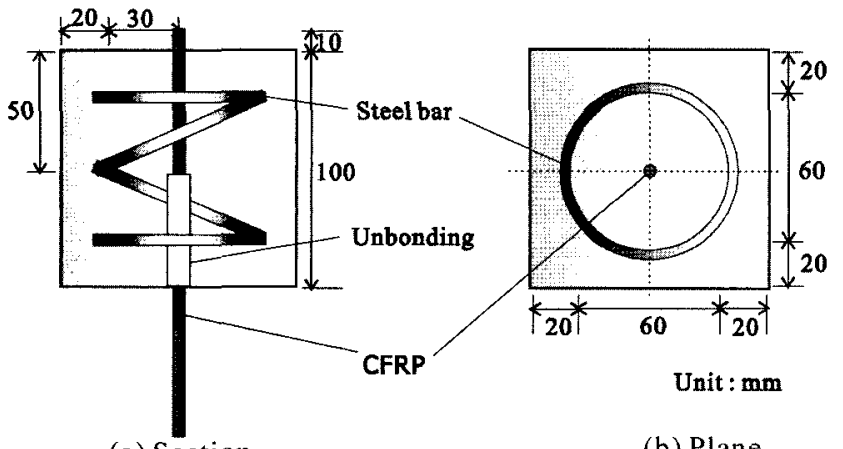

(a) Section

(b) Plane

Fig. 4 Details of specimen. ${ }^{9}$

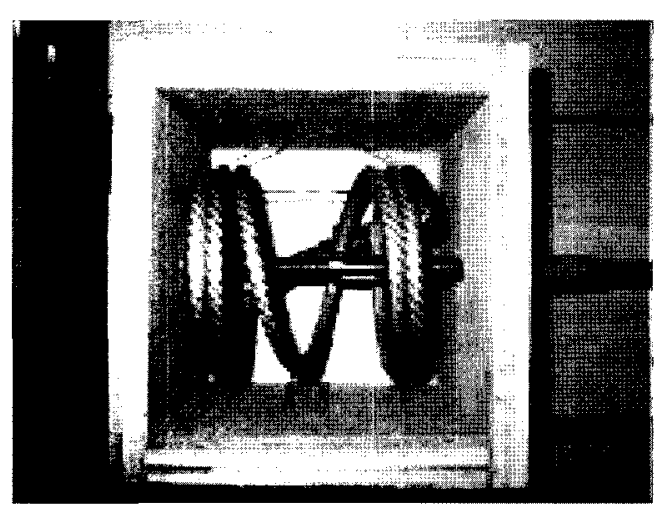

Fig. 5 Specimen in mold, ready for casting. ${ }^{9}$

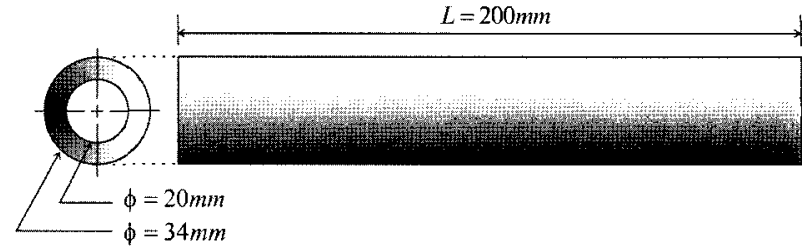

Fig. 6 Geometry of anchorage sleeve.

\section{Experimental results}

The most significant observations on the effect of these parameters are summarized in the following section.

\subsection{Bond strength}

Average bond stress $\tau$ was determined using Eq. (1) based on the maximum pullout load $P_{\max }$, assuming a uniform bond stress distribution along the embedded length of the rod in the concrete. The bond stress was calculated using the nominal rod diameter $d$, although for some of the rods the actual diameter of some rods was larger than the nominal one. Test results on CFRP rods as well as steel bars are presented in Table 5 .

$$
\tau=\frac{p_{\max }}{\pi d l}
$$

To illustrate the effect of the test parameters on the maximum bond strength, the splitting bond strength $\tau$ in all test series were plotted according to the rib spacing to rod (s) as shown in Fig. 8. Based on the trend of experimental results, the following relationship is proposed to calculate the splitting bond strength $\tau(\mathrm{MPa})$.

$$
\begin{aligned}
& \frac{\tau}{\left(f^{\prime}{ }_{c k}\right)^{1 / 2}}=0.5571(\mathrm{~s})^{0.4157} \\
& \tau=0.5571\left(f_{\mathrm{ck}}\right)^{1 / 2}(\mathrm{~s})^{0.4157}
\end{aligned}
$$

where, $\tau=$ bonding stress

$$
\begin{aligned}
& f_{\mathrm{ck}}^{\prime}=\text { compression strength of concrete } \\
& s=\text { rib spacing }
\end{aligned}
$$

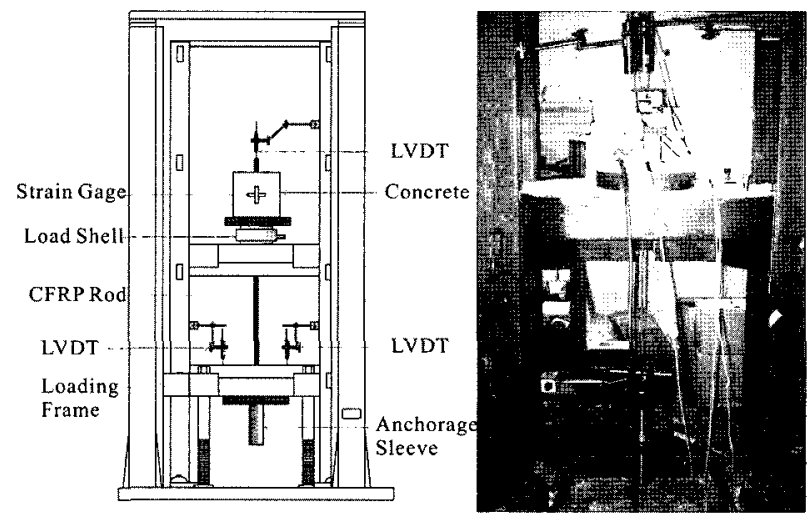

Fig. 7 Loading system and specimen under testing photograph. 
Table 5 Summary of pullout test result of CFRP.

\begin{tabular}{c|c|c|c|c}
\hline Types & Pitch of helical wrapping $(\mathrm{mm})$ & Diameter $(\mathrm{mm})$ & Embedded length $(\mathrm{mm})$ & Bond stress (average) (MPa) \\
\hline \hline CF10 & 10 & 7.57 & 50 & 7.08 \\
\hline CF20 & 20 & 6.64 & 50 & 12.06 \\
\hline CF30 & 30 & 6.47 & 50 & 12.68 \\
\hline CF40 & 40 & 6.72 & 50 & 12.30 \\
\hline SB & Steel bar & 6.4 & 50 & 9.76 \\
\hline
\end{tabular}

※ $\mathrm{P}_{\max }$ : initial yield point

The above equation describing the characteristic properties between bond stress and slip has properties of concrete (concrete strength) and rib spacing of rod as the variables of the equation. The proposed bond model described above is capable of predicting the results of this limited experimental study on the bond strength of reinforcing bars.

\subsection{Stress-slip relationship}

The stress-slip relationships are presented in Fig. 9. Notice that the curve for pullout behavior seems to have a long gently curving "tail". This indicates a behavior that is distinctly different from either concrete or carbon fiber. The slope of the curve can be considered to be the bond stiffness because it gives a relationship between stress and deformation. The value has an important effect on the width of primary flexural cracks in reinforced concrete and on the deflection of beams and slabs. Initial bond stiffness of all specimen types was nearly the same up to a proportional limit, and the significant effect of the pitch of helical wrapping to the bonding behavior could not be found. When bond stress reaches hardening area, specimen CF20 that contains $20 \mathrm{~mm}$ pitch of helical wrapping had the highest strength of all, and next strongest specimen was CF40.

From the results discussed above, it may be concluded that the pitch of helical wrapping strand influences the slip-bond behavior of CFRP rods. While the bond stiffness of CF20 after initial yield point was higher than others, but all these specimens exhibited higher bonding stiffness capacity than steel bars.

\subsection{Surface examination}

The surface of the rod was examined after pullout to evaluate the damage to the rod and its surface during pullout. The images of the rods after pullout are presented in Fig. 10.

The surface of the CFRP rods after pullout showed that the whole external layer of carbon fiber sheared away from the core and helical fiber wrapped around the surface were damaged due to

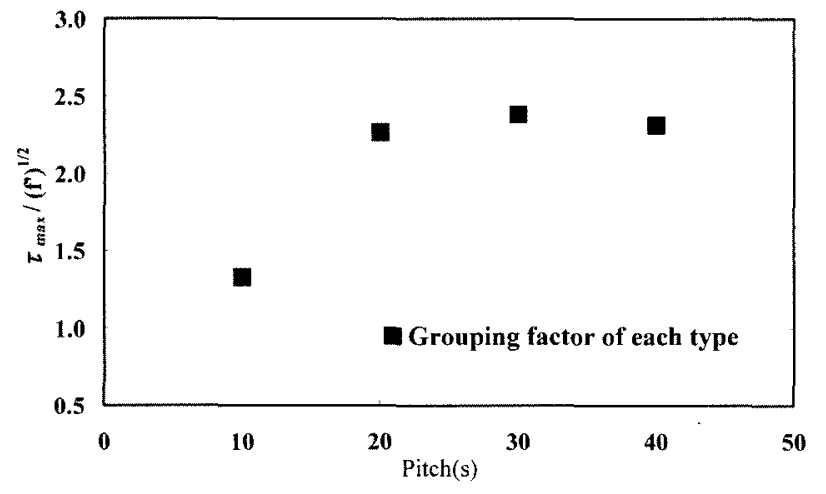

Fig. 8 Grouping factors curve. the shear stress concentrated on the helical wrapping. It seems that weak adhesion between the external layer and the core was the main reason for bond failure of this rod. Examination of the surface of steel bars after pullout showed residues of concrete, filling the areas between the deformations of the steel for all the rods regardless of loading. It seems that in all cases the layers of concrete filling the spaces between the deformations sheared and failed without damaging the steel.

Failure of the polymer at the surface of the rod is observed for the rods CF20, CF30 and CF40 and is described schematically in Fig. 11. During initial pullout, the chemical bond (adhesion, $\tau_{w}$ ) of wrapping strand is the main resisting mechanism for extemal force(T); afterwards, it is replaced by friction and /or mechanical interlock $\left(\tau_{c f}\right)$ of helical wrapping strand. Since the chemical bond between concrete and CFRP rods is generally low, friction and mechanical interlock really become the primary mechanism of stress transfer.

During loading, only the upper areas of the rod between the helical windings were in contact with concrete after initial bond failure between the two. Thus these areas were damaged significantly during the loading, whereas the lower areas of the surface, near the helical windings, were damaged a little.

The damage during pullout of the CF40 propagated to the wrapping strand as well as helical wrapping strand. However, CF20 characterized by a strong and stiff wrapping strand and helical wrapping strand provided the high bond value after bond stress reached the yield point. Helical wrapping strand sheared partially, leaving its residues on the lower areas and most of wrapping strand and leading to a significant increase in the bond strength of the plastic area. Additionally, it seems that a large number of helical wrapping strands contributed to the bond of CF20 for the fact that they did not shear from the core of rod due to the confinement effect of the helical wrapping strands manufactured carefully under constant tensile force.

To understand both mechanisms, some specimens were subjected to further inspection after the experiment. Specimens

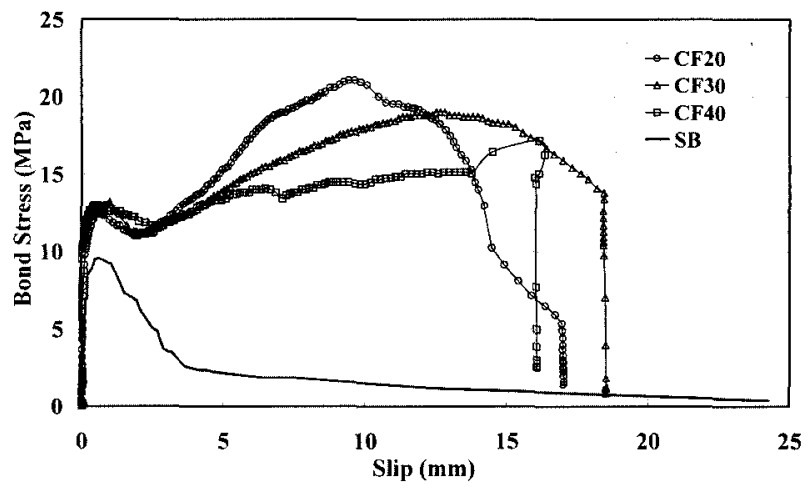

Fig. 9 Curves of bond stress-slip of tested rods. 
were cut into two parts. The images of the section of concrete cut after pullout are presented in Fig. 12. The outer surface of the CFRP reinforcement rod and the surrounding concrete within the embedded portion were observed, thus providing useful information about the interaction. The contact surface between concrete and CFRP rod turned to black due to serious friction.

\section{Conclusions}

Bond properties for three types of Super CFRP rods with different pitch of helical wrapping and one type of deformed steel bar were analyzed experimentally. The major conclusions of this paper are:

1) Initial bond stiffness of all types was nearly the same up to a proportional limit, and the effect of the pitch of helical wrapping on the bonding behavior was found insignificant. When bond stress reached the hardening area of specimen CF20 with $20 \mathrm{~mm}$ spacing of helical wrapping, it showed the highest strength of all, and the next highest strength was exhibited by the specimen type CF30.

2) The stress-slip relationship of the specimen of embedded cables within concrete was linear up to the maximum bond capacity.

3) The average bond capacity of CF20, CF30 and CF40 were about $12.06 \mathrm{MPa}, 12.68 \mathrm{MPa}$ and $12.30 \mathrm{MPa}$, respectively. It was found that helical wrapping was sufficient to yield bond strengths comparable to that of steel bars.

4) The mechanical properties of the external layer of the CFRP rods had an important effect on the bond of these rods to concrete, after the bond stress reached the yield point.

5) Unlike the CFRP rods with helical wrapping, the damage by the pullout of deformed steel was located solely in the surrounding concrete regardless whether only the rod or both the rod and surrounding concrete was damaged, leading to a sudden drop in the load after the peak load was attained.

6) All types of CFRP rods showed a great initial stiffness and good ductility. The deformation capacity within the range of maximum force seemed very low and was reached after approximately $1 \mathrm{~mm}$. These results are as expected in that the

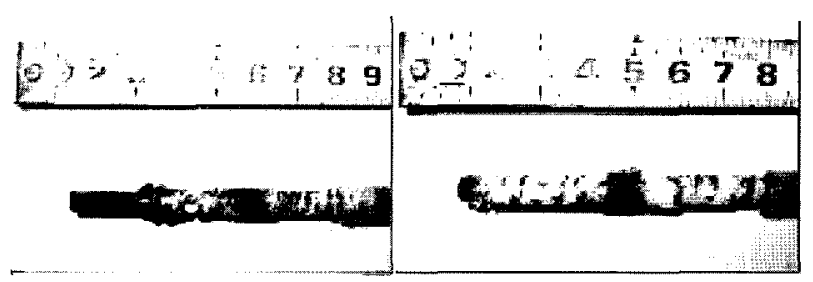

(a)CF20

(b)CF30

Fig. 10 Damage to rods after pullout.

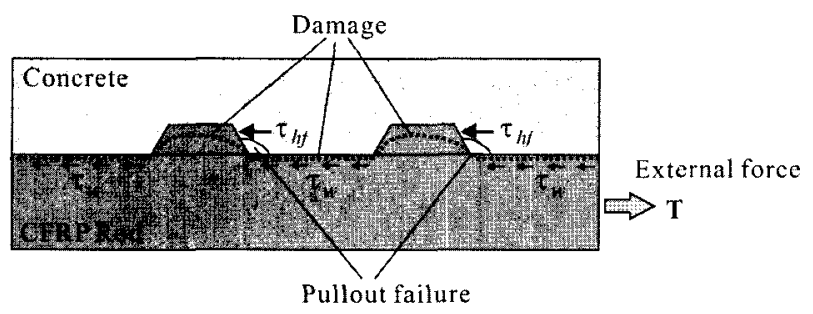

Fig. 11 Description of failure of rods.

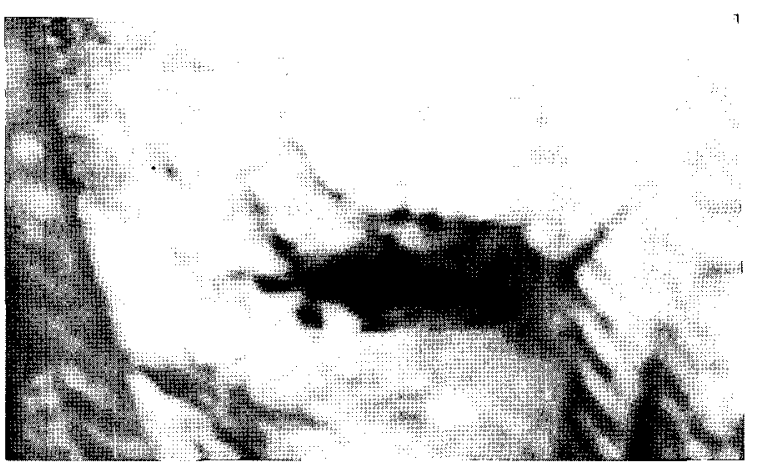

Fig. 12 Damage to concrete after pullout.

failure can be explained by the slip between core and helical wrapping strand of CFRP rod.

7) Based on the experimental result, the relationship between $\operatorname{stress}(\tau)$ and the rib spacing to rod is proposed.

\section{Acknowledgement}

The author would like to thank Prof. Toshiaki Ohta for his valuable help, and also wishes to express a sincere appreciation to Rudy Djamaluddin and Basem Abdullah for their suggestions regarding the test method.

\section{References}

1. Chajes, M. J., Finch, W. W., Januszka, T. F., and Thomson, T. A., "Bond and Force Transfer of Composite-Material Plates Adhered to Concrete," Structural Journal, ACI, Vol.93, No.2, 1996, pp.208 217.

2. Nanni, A., Al-Zaharani, M. M., Al-Dulaijan, S. U., Bakis, C. E., and Boothby, T. E., "Bond of FRP reinforcement to concreteexperimental results," Proc., 2nd Int. RILEM SYMP., L. Tarewe, ED., E \& FN Spon, London, 1995, pp.135 145.

3. Benmokrane B., Tighiouart, B., and Chaallal, O., "Bond strength and load distribution of composite GFRP reinforcing bars in Concrete," ACI Mat. J., Vol.93, No.3, 1996, pp.246 253.

4. Cosenza, E., Manfredi, G. and Realfonzo, R., "Behavior and modeling of bond of FRP rebars to concrete," $J$. Compos. for Constr., ASCE, Vol.1, No.2, 1997, pp.40 50.

5. Burgoyne, J. M., and Lees, C. J., "Experimental study of influence of bond on flexural behavior of concrete beams pretension with aramid fiber reinforced polymer," $A C I$ Structural Journal. Vol.96, No.3, 1999, pp.377 385.

6. Ayman, M. O., Mohsen, S., and Sherif, E. T., "Short-term tensile strength of carbon fiber-reinforced polymer laminates for flexural strengthening of concrete girders," ACI Structural Journal, Vol.98, No.4, 2001, pp.470 478.

7. Abdullah, B., Fundamental study on strengthening of steel girder bridge with RC slab by using pultruded GFRP members, $\mathrm{PhD}$ dissertation, University of Kyushu, Fukuoka, Japan, 2001, pp.l 8.

8. Ohta, T., Djamalluddy, R., Seo, S. T., Sajima, T., and Harada, K., "Evaluation of tensile strength of unresin continuous carbon fiber cables are tensile reinforcement for concrete structure," Memoirs of the Faculty of Engineering, Kyushu University, Vol.62, No.4, 2002, pp.179 190.

9. JSCE-E 539, "Quality Specifications for Continuous Fiber Reinforcing Materials," Concrete Library of JSCE, 1996, pp.55 129.

34 | International Journal of Concrete Structures and Materials (Vol.18 No.1E, June 2006) 